\title{
Columnar cell variant of papillary thyroid carcinoma - a rare and clinically aggressive variant
}

\author{
I.H.D.S. Pradeep ${ }^{1}$, P.C. Chandrasingha ${ }^{2}$, K.R. Kannangara ${ }^{1}$, E.K.G.D.C. Epitakaduwa ${ }^{3}$, R.F. Fernando ${ }^{2}$ \\ 1Professorial Surgical Unit NCTH Ragama \\ 2Department of Surgery, University of Kelaniya. \\ 3Department of Pathology,University of Kelaniya.
}

\section{Introduction}

Columnar variant of Papillary thyroid carcinoma (PTC) is a rare variant representing $0.15-0.2 \%$ of all PTC (figure 1) with an aggressive behavior and high mortality[5]. We discuss two cases of columnar variant ofPTC reported with in a period of 12 years.

\section{Case 1}

$24 y r$ old female presented with an anterior neck lump for 3 weeks duration; was found to have solitary nodule on right lobe of the thyroid gland without palpable cervical nodes. She was biochemically euthyroid and Fine Needle Aspiration cytology (FNAC) of the solitary nodule revealed PTC with background autoimmune thyroiditis. She was diagnosed with Familial adenomatous polyposis coli; with a history of subtotal colectomy for moderately differentiated adenocarcinoma of the cecum (T4N1Mx) one year back. She underwent total thyroidectomy with level VI nodal clearance. Histopathology reveled columnar cell variant of PTC without Capsular or vascular invasion or excision margin involvement. She received radioactive Iodine treatment following surgery and was followed up at cancer institute. 9 months following the thyroid surgery she was found to have vertebral metastasis which was histologically confirmed as metastatic PTC deposit. Irrespective of oncological management she died 15 months following thyroid surgery.

Case 2

Second patient was a 35 year old male presented with a goiter for four years duration. He had compressive symptoms and was clinically euthyroid. On clinical

Correspondence: I.H.D.SPradeep

E-mail: samaniddagoda@gmail.com examination he had a multinodular goiter without cervical lymphadenopathy. He was biochemically euthyroid and FNAC revealed a Thy 2 leision. Patient underwent total thyroidectomy and Histopathology confirmed the presence of a PTC of columnar cell variant. Microscopically there was capsular and vascular invasion and tumor staged as T2NxMx. Patient was referred for radioactive iodine therapy at cancer institute.

\section{Discussion}

Columnar cell variant of PTC is an aggressive sub type due to its rapid growth, high local recurrence rate, and frequent lung, brain and bone metastases [3]. Aggressive surgical and medical management are recommended for these tumors ones it has been diagnosed [3].Total thyroidectomy with central compartment neck dissection, lymphadenectomy, and/or resection of invaded surrounding structures is the recommended surgical management [4]. Postoperative radioactive iodine is advocated for these tumors since they are generally intermediate to advanced tumors with distant metastasis [4].

It is uncommon to have Columnar cell variant of PTC in association with FAP as reported in first patient. Female predominance, Multicentricity, early lymph node involvement and early age of onset, are the recognized clinicopathological features of FAP-associated thyroid carcinoma and Cribriformmorular variant of PTC is the commonest variant among them [2].

In diagnosing thyroid malignancies and differentiation of their subtypes multiple immunohistochemical markers are used [1]. A nuclear transcription factor; $\mathrm{CDX} 2$ is shown to be selectively expressed in $55 \%$ of cases of columnar variant of PTC [1]. It can be used as an immunohistochemical marker in 
combination with histopathology to distinguish columnar variant from other variants of PTC.

\section{Conclusion}

Columnar variant of papillary carcinoma is a rare and aggressive variant of PTC and has poor prognosis compared to conventional PTC. Once diagnosed patient needs aggressive treatment with tight follow-up compared to other variants of PTC.

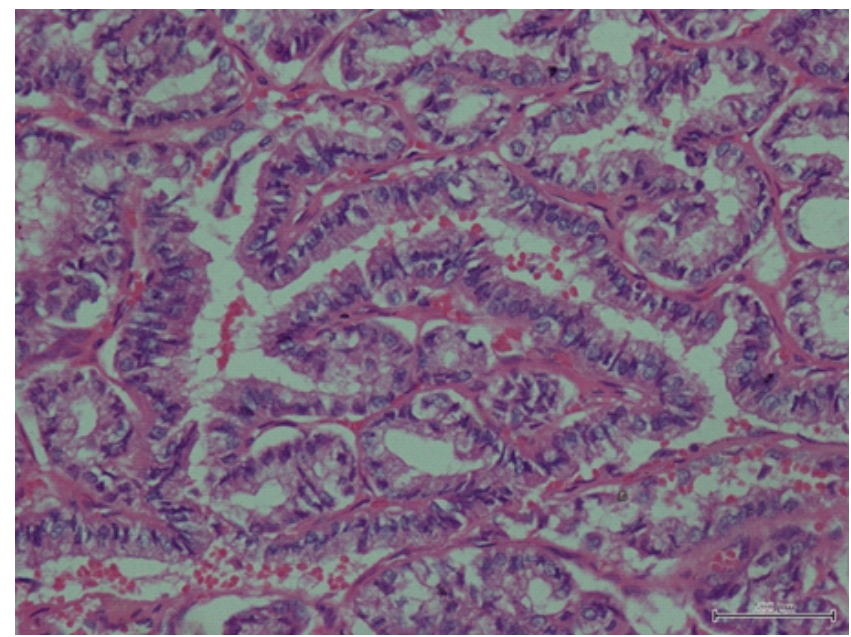

figure 1. Histopathological specimen of Columnar cell variant of PTC

\section{References}

1. Miriam L. Enriquez, Zubair W. Baloch, Kathleen T. Montone, Paul J. Zhang, Virginia A. LiVolsi: CDX2 Expression in Columnar Cell Variant of Papillary Thyroid Carcinoma .American Journal of Clinical Pathology doi: 10.1309/AJCPXE3PUBWVZCGZ (2012) American Journal of Clinical Pathology 137, 722-726.

2. Kimberly A. Donnellan, Steven A. Bigler, Richard O. Wein: Papillary thyroid carcinoma and familial adenomatous polyposis of the colon. American Journal of Otolaryngology - Head and Neck Medicine and Surgery 30 (2009) 58-6.

3. ZubairBaloch, Virginia A LiVolsi, RashmiTondon: Aggressive Variants of Follicular Cell Derived Thyroid Carcinoma. The So-Called 'Real Thyroid Carcinomas. $J$ Clin Pathol 2013;66(9):733-743.

4. Silver CE, Owen RP, Rodrigo JP, Rinaldo A, Devaney KO, Ferlito A:Aggressive variants of papillary thyroid carcinoma. Head Neck. 2011 Jul;33(7):1052-9. doi: 10.1002/hed.21494.

5. Kazaure HS, Roman SA, Sosa JA:Aggressive variants of papillary thyroid cancer: incidence, characteristics and predictors of survival among 43,738 patients. Ann Surg Oncol 2012 Jun; 19(6):1874-80. doi: 10.1245/s10434-0112129-x

\section{Key Points:}

- Columnar cell variant of papillary thyroid cancer is a rare variant with an aggressive clinical behavior and high mortality.

- Once diagnosed these patients needs aggressive treatment with tight follow up compared to other variants of PTC. 